\title{
O ENSINO E AS PROFISSÕES JURÍDICAS NOS EUA E NA INGLATERRA: PERFIL GERAL
}

\section{THE EDUCATION AND THE LEGAL JOBS IN USA AND ENGLAND: GENERAL PROFILE}

\author{
Thaís Xavier Ferreira da Costa ${ }^{1}$ \\ Cassia Alves Moreira Denck ${ }^{2}$
}

\section{RESUMO}

O presente trabalho tem por objetivo apresentar um estudo compilado da organização judiciária e das carreiras jurídicas nos Estados Unidos da América e na Inglaterra, procurando identificar suas estruturas judiciárias e seu histórico, a disciplina da advocacia e das atividades decorrentes do sistema de Direito, além de traçar o perfil do ensino jurídico comparando suas metodologias e os seus reflexos nas profissões jurídicas. Ao final, identificam-se pontos de convergência dentro do Sistema Commom Law, comparando-o nos aspectos abordados com o Sistema em vigência no Brasil. Para tanto, será utilizada a metodologia bibliográfica exploratória, pautada em obras doutrinárias e demais estudos científicos.

Palavras-chave: Metodologia; Ensino; Profissões Jurídicas

\begin{abstract}
This study aims to present a compiled study of the judicial system and the legal profession in the United States and England, seeking to identify their judicial structures and their history, the discipline of law and the activities resulting from the system of law, and profile the legal education comparing their methodologies and their reflections in the legal professions. At the end, they can identify points of convergence within the Common Law system, comparing it to the points raised with the system in force in Brazil. Therefore, the exploratory literature methodology, based on doctrinal works and other scientific studies will be used.
\end{abstract}

Keywords: Methodology; Teaching; Lawyers

\section{INTRODUÇÃO}

\footnotetext{
${ }^{1}$ Mestranda em Ciências Jurídicas pela UNICESUMAR - Centro Universitário Cesumar. Auditora Estadual de Controle Externo junto ao Tribunal de Contas do Estado de Mato Grosso do Sul (Brasil). E-mail: thaiscosta@tce.ms.gov.br

2, Especializanda em Direito de Família e Sucessões pela Faculdade de Direito Professor Damásio de Jesus, Mestranda em Ciências Jurídicas pela UNICESUMAR - Centro Universitário Cesumar. Atualmente Estagiária de Pós-Graduação junto ao Ministério Público do Estado do Paraná (Brasil). E-mail: cassiadenck@gmail.com
} 
A diversidade de direitos no mundo é objeto estudo e classificações, mormente no que diz respeito às estruturas judiciárias, ao ensino e às profissões jurídicas. Implícito ao tema, tangenciando seu entendimento, tem-se o estudo das metodologias empregadas e a busca da sua influência, se romano-germânico ou se pertinente a common law. Pela sua tradição e repercussão mundial, os Estados Unidos da América e a Inglaterra são referências de estudo por renomados doutrinadores.

Nessa perspectiva, o trabalho em apreço tem por objetivo apresentar um estudo compilado da organização judiciária e das carreiras jurídicas nesses dois países. Almeja-se, especificamente, comparar suas metodologias no que diz respeito ao ensino jurídico e ao reflexo nas profissões jurídicas.

Fundamenta-se a pesquisa e centra-se sua investigação na identificação do sistema da Commow Law no ensino e nas profissões jurídicas dos Estados Unidos da América e da Inglaterra.

Para tanto, será utilizada a metodologia bibliográfica exploratória, pautada em obras doutrinárias e demais estudos científicos acerca do tema, iniciando com o esboço dos sistemas e seus métodos, bem como da estrutura judiciária dos dois países. Na sequência, passa-se à tratativa do ensino nas grandes universidades, evoluindo para o exercício da advocacia nesses países.

Trata-se, com efeito, de um trabalho que busca estudar esses sistemas de ensino jurídico e, via de consequência, do exercício das atividades jurídicas, a partir da análise dos métodos, currículos e atividades das principais Universidades de Direito da Inglaterra e dos Estados Unidos da América, bem como da atuação de suas entidades e Cortes reguladoras da profissão.

Sem a pretensão de esgotar o tema ou dar-lhe um novo enfoque, o trabalho em apreço buscará nos referenciais teóricos acerca da matéria traçar um perfil geral desses dois países, sempre que possível buscando nas suas raízes históricas e na sua posição hodierna, um parâmetro de comparação com o nosso sistema pátrio.

\section{TRIBUNAIS DA COMMON LAW E EQUITY}


Para compreensão e alcance da pesquisa em apreço, mister se faz um sucinto estudo acerca do sistema da Common Law, que na perspectiva histórica, explica a construção do ensino, da organização judiciária e das profissões jurídicas nos EUA e na Inglaterra.

Historicamente, o embasamento de Common Law é o de um direito oriundo das sentenças judiciais dos Tribunais de Westminster, Cortes essas constituídas pelo Rei, com o escopo de impor uma lei comum a toda Inglaterra. Tais Cortes estavam subordinadas diretamente ao Rei, de forma que suas decisões acabaram por suplantar os direitos costumeiros e particulares de cada tribo dos primitivos povos da Inglaterra (estes, portanto, antes da conquista normanda em 1066, denominado direito anglo-saxônico).

Entretanto, desde o século XIV, os particulares, não podendo obter justiça através dos Tribunais Reais, ou quando inconformados com a solução dada à sua causa por esses tribunais, dirigiam-se ao rei para solicitar uma intervenção. Esse pedido passava então pelo Chanceler $^{3}$, e este dizia ao rei se o novo julgamento era oportuno, decidindo-se no seu próprio Conselho a solução. Com efeito, o Chanceler foi tornando-se cada vez mais um juiz autônomo e sua intervenção foi cada vez mais solicitada.

Surge então, ao lado o common law, um sistema costumeiro e fechado, a Equity, um sistema jurídico emergente das decisões dos Tribunais do Chanceler do Rei, inspirado em princípios do direito canônico, que conferia à comunidade inglesa um sentimento de justiça. É o que explica René David ${ }^{4}$ :

O sistema inglês possuía e ainda possui um sistema dualista. Ao lado das regras da common law, que são obras dos Tribunais Reais de Westminster, também designados por tribunais da common law, ele apresenta soluções de equity, que vieram complementar e aperfeiçoar as regras do common law. A característica dessas soluções de equity foi, até 1875, a circunstância de serem aplicadas exclusivamente por uma jurisdição especial: o Tribunal de Chancelaria.

Destarte, em que pese o triunfo da jurisdição da equidade no período de 1485-1832, o conservadorismo do povo inglês levou à extinção dos Tribunais de Chancelaria, mas com o compromisso de fazer subsistir, lado a lado, em equilíbrio de forças, os tribunais da commow law e a jurisdição do Chanceler, o que perdurou até 1875:

\footnotetext{
${ }^{3}$ A partir de 1529 o Chanceler tornou-se um jurista, seguindo um processo inspirado no direito canônico, inteiramente diferente dos tribunais da common law.

${ }^{4}$ DAVID, Rene. Grandes sistemas do direito contemporâneo. 4. ed. São Paulo: Martins Fontes, 2002. p. 374375 .
} 
Contudo, as soluções equity tornaram-se, com o decorrer dos séculos, tão estritas, tão jurídicas como as da common law e a sua relação com a equidade não permaneceu muito mas íntima do que no caso das regras common law. A equity inglesa é, no seu ponto de vista, a equidade tal como foi possível conceber no século XVI, e na medida em que foi possível ao Chanceler realiza-la. Tais ressalvas não podem ser perdidas de vista. Os Tribunais ingleses consideram com muita ponderação, nos nossos dias, as sugestões que lhe são feitas para continuar a obra do Chanceler nos séculos XV e XVI, e para desenvolver ousadamente novas doutrinas de equidade. A equity parece-lhes um conjunto de regras que vieram corrigir historicamente o direito inglês, e que constituem hoje uma peça integrante do mesmo. As razões que outrora justificaram a intervenção do Chanceler já não existem: o parlamento poderá intervir se o direito inglês necessitar de um aperfeiçoamento. A segurança das relações jurídicas e a supremacia do direito seriam ameaçadas se, sob o pretexto da equidade, os juízes ingleses aceitasse colocar em discussão as regras de direito estabelecidas e os juízes manifestaram, de maneira clara, em fórmulas surpreendentes, a sua determinação de não seguirem este caminho.

Conforme o exposto, desde a reforma da estrutura judiciária (1873-1875), formalmente suprimiu-se a distinção formal dos Tribunais de Common Law e do Tribunal de Equity de Chancelaria. Entretanto, o direito inglês possuía um sistema claramente dualista: a par das regras da common law, de base consuetudinária, produto da construção e consolidação jurisprudencial dos Tribunais Reais do século XIII, subsistiram numerosas doutrinas de Equity, fruto da jurisdição pessoal do monarca ou do chanceler, nos séculos XV e XVI, que se destinaram precipuamente a corrigir ou acrescentar institutos jurídicos à common law.

Consoante o exposto, é a Equity, uma realidade jurídica estritamente inglesa, um peculiar sistema de direito criado em função da common law, e atualmente, a ela integrada. Hodiernamente, qualquer aperfeiçoamento que se faça necessário fica a cargo do Parlamento inglês.

A par desse breve apanhado histórico e sem nos aprofundar nos meandros do período moderno, passa-se ao estudo da estrutura judiciária da Inglaterra e dos E.U.A.

\section{ESTRUTURA JUDICIÁRIA DA INGLATERRA E DOS ESTADOS UNIDOS DA AMÉRICA}


Bem diferente da nossa organização, o Direito Inglês tem na seara do Judiciário ${ }^{5}$, dois tipos de jurisdições: Cortes Superiores de um lado (que são as Cortes que resolvem os litígios e representam o Judiciário, também encarregadas de dizer o que é direito), e as Cortes Inferiores de outro (estas apenas resolvem o litígio). O Poder Judiciário controla a legalidade dos atos da administração, intervindo por ordens mandamus ou de prohibition, para ordenar que a administração cumpra um ato que lhe é imposto pelo direito ou para vedar-lhe um comportamento ilegal.

Emprestemo-nos, na oportunidade, das lições de José Rogério Cruz e Tucci ${ }^{6}$, para transcrever a estrutura das cortes judiciárias britânicas na atualidade:

1. Supreme Court of the United Kingdom - tribunal mais elevado da hierarquia judiciária britânica, formado por doze magistrados (Law Lords) indicados pela Rainha, aconselhada pelo Primeiro Ministro ou pela Judicial Appoints Comission. Sucede ao Appellate Committee of the House of Lords, extinto em $1^{\circ}$ de outubro de 2009 por força do Constitutional Reform Act 2005, que concedeu ao órgão estrutura política independente, de sorte a não mais integrar o Parlamento britânico. Por essa razão histórica, a jurisprudência e doutrina anteriores ao ano de 2005 fazem referência ao comitê específico da House of Lords como a instância máxima de julgamento na Inglaterra;

2. Supreme Court of Judicature - situada em grau imediatamente inferior à Suprema Corte do Reino Unido, compõe-se de dois principais órgãos de julgamento, a 1) High Court of Justice e a 2) Court of Appeal, presidida pelo Master of the Rolls. Estas, por sua vez, se organizam em Divisions, algumas especializadas em determinadas matérias. A High Court é seccionada em três órgãos colegiados, a saber, a i) Queen's Bench Division, a ii) Chancery Division e a iii) Family Division. O Queen's Bench, de seu turno, divide-se na i.1) Commercial Court e na i.2) Admiralty Court;

3. Crown Court - subordinada à High Court, é encarregada do julgamento em primeira instância das causas criminais. Encontra-se espalhada pela Inglaterra e País de Gales na forma de aprox. 90 (noventa) juízos;

4. County Courts - competentes para o processo e julgamento, em primeiro grau, das causas cíveis no valor de até 50.000 Libras. No ano de 2010, alcançavam o número de 216 (duzentos e dezesseis) juízos, na Inglaterra e no País de Gales. Encontram-se regulados pelo County Courts Act 1984 e são administrados pelo Her Majesty's Courts Service, subordinado ao Ministério da Justiça do Reino Unido.

No que diz respeito à organização judiciária dos Estados Unidos da América, a jurisdição é dividida em federal e estadual, conforme explica R. David

\footnotetext{
${ }^{5}$ Em relação ao nível das grandes distinções do Direito, não encontramos a classificação público e privado, por exemplo. Em lugar dessas grandes classificações, encontramos outras, como common law e equity.

${ }^{6}$ TUCCI, José Rogério Cruz e (coord.). Direito processual civil europeu contemporâneo. São Paulo: Lex, 2010. p. 218-219.

${ }^{7}$ DAVID, Rene. Grandes sistemas do direito contemporâneo. 4. ed. São Paulo: Martins Fontes, 2002. p. 478479.
} 
A organização judiciária dos Estados Unidos comporta, por um lado, jurisdições feitas, e por outro, jurisdições dependentes dos Estados. Diferentemente daquilo que se passa em numerosos Estados federais (Alemanha Federal, Austrália, Canadá, Suíça, União Soviética), onde apenas se encontra uma jurisdição federal no cume da hierarquia, os Estados Unidos adotaram um sistema completamente diverso: os pleiteantes podem, em numerosos casos, desde logo submeter a apreciação dos litígios em primeira instância à jurisdições federais. Existe, por consequência, nos Estados Unidos, uma dupla hierarquia em que cada uma deve ser objeto de si mesma, antes de se averiguar a relações existentes entre elas.

Em conformidade com o Federal Judicial Center $^{8}$, a estrutura judiciária dos Estados Unidos da América encontra-se assim organizada:

1. Supreme Court of the U.S. - situada no ápice do sistema normativo estadunidense, é composta de 9 (nove) ministros (justices) que tratam dos casos de maneira conjunta. A seu próprio critério, a Suprema Corte dos Estados Unidos pode aceitar recursos oriundos dos vários tribunais regionais, assim como das varas da mais alta instância estadual, se os mesmos tiverem relação com a Constituição dos EUA ou leis federais;

2. District Courts ou Circuit Courts - juízos federais de primeira instância, em número de 94 (noventa e quatro), espalhados por todo o País. Cada estado conta com pelo menos um juízo federal. Os juízes federais (district judges) trabalham individualmente em seus diversos casos. Além deles, os juízos federais também incluem juízes de falências (de competência exclusivamente falimentar) e os magistrate, ou juízes de pequenas causas, que cuidam de várias tarefas judiciais sob a supervisão geral dos juízes federais;

3. Courts of Appeals - tribunais federais de recursos, também chamados de circunscrições, no total de 12 (doze), em diversas regiões do País. Recursos oriundos dos juízos federais são analisados por painéis compostos de três juízes. Não se admite ao Estado recorrer em feitos criminais quando o veredicto é "não culpado". Admitem-se, nos tribunais regionais, recursos de decisões tomadas por órgãos administrativos federais. Um dos tribunais federais não é regional (Federal Circuit) e possui competência recursal para casos especializados, como demandas que envolvam leis de patentes e ações contra o governo federal;

4. U.S. Bankruptcy Courts - tribunal federal especializado em matéria falimentar. Cada um dos 94 distritos judiciais federais lida com questões de falência, mas, em quase todos os distritos, casos de falência são concluídos no tribunal de falência. Nos Estados Unidos, a matéria falimentar é de competência exclusiva da Justiça Federal;

5. U.S. Courts of Special Jurisdiction - Justiça especializada por matéria, mantida pelo governo federal norte-americano, composta da U.S. Court of Appeals for the Armed Forces (militares), U.S. Court of Federal Claims (demandas contra o governo federal), U.S. Court of International Trade (comércio internacional), U.S. Tax Court (matéria tributária), U.S. Court of Appeals for Veterans Claims (ex-combatentes) e o Judicial Panel on Multidistrict Litigation (questões de competência jurisdicional de feitos cíveis conexos pendentes em diferentes juízos federais);

${ }^{8}$ FEDERAL JUDICIAL CENTER. Sistema jurídico dos Estados Unidos: uma breve descrição. Disponível em: http://www.fjc.gov/public/pdf.nsf/lookup/Portuguese01.pdf/\$file/Portuguese01.pdf Acesso em 12/03/2016. 
6. Justiça Estadual - a estrutura dos sistemas de tribunais estaduais varia conforme o estado. A maioria dos estados tem juízos de jurisdição limitada, presididas por um único juiz que cuida de casos menores, tanto cíveis quanto criminais. Os estados têm juízos de primeira instância (trial courts), de competência geral, que são presididos por um único juiz. São geralmente chamados de circuit courts (comarcas ou circunscrições) ou superior courts e cuidam de casos graves, tanto civis quanto criminais. Alguns estados têm também uma vara intermediária de recursos chamada court of appeals, que cuida de recursos oriundos dos juízes de primeira instância. De um modo geral, qualquer parte envolvida em um determinado caso conta com um direito de apelação.

Como bem observa R. David ${ }^{9}$, um ponto de divergência entre a organização judiciária inglesa e a dos E.U.A. funda-se na centralização muito menor do Poder Judiciário americano que no inglês. A justiça inglesa está concentrada em Londres, com raríssimas exceções. Já nos E.U.A., por razões históricas e geográficas existem jurisdições próprias para cada Estado, ao lado de uma multiplicidade de jurisdições federais em todo território da União, e não apenas na capital federal.

\section{AS PROFISSÕES JURÍDICAS}

Esta breve incursão nas profissões jurídicas da Inglaterra e dos Estados Unidos da América, busca traçar alguns de seus requisitos e revelar os papeis desempenhados frente às suas Justiças, buscando sempre que possível, correlacionar dentro de uma perspectiva histórica, a sua atuação com o ocorrido no ordenamento pátrio.

\subsection{OS BARRISTERS (OU CONSELS) E OS SOLICITORS, E A FORMAÇÃO E EXERCÍCIO PROFISSIONAL DOS ADVOGADOS E MAGISTRADOS INGLESES (ATTORNEY)}

$\mathrm{Na}$ Inglaterra, em conformidade com o que explica a doutrina de R. David ${ }^{10}$, os profissionais do Direito são agrupados em duas categorias:

a) Uns chamados barristers (ou counsel), que correspondem aos nossos advogados; e

\footnotetext{
${ }^{9}$ DAVID, Rene. Grandes sistemas do direito contemporâneo. 4. ed. São Paulo: Martins Fontes, 2002. p. 484

${ }^{10}$ DAVID, Rene. O Direito inglês. São Paulo: Martins Fontes, 1997. p. 33.
} 
b) Os outros, chamados solicitors, que desempenham funções que cabem, na França, aos auxiliares de justiça, notadamente aos avoés (profissionais de direito cuja função é a de proceder a todos os atos processuais em segunda instância) e aos tabeliões.

Os solicitors dizem respeito a outra vertente da profissão, e estão espalhados pelo país, com a função de se relacionarem com o cliente. Com efeito, os advogados não entram em contato diretamente com seus clientes, e é tão somente com a interveniência dos solicitors que são postos a par das causas que devem defender. São igualmente os solicitors que cuidam do andamento do processo, em particular entrando em contato com as testemunhas, cujos depoimentos serão utilizados pelo advogado na audiência.

Havia, em 1974, 28.741 solicitors na Inglaterra, e o número dos que efetivamente praticavam a atividade de advogado (barristers) era, nessa mesma época, de 3.377, dos quais 952 estavam estabelecidos no interior.

Em geral, os solicitors estão agrupados em escritórios, onde uns tratam das causas contenciosas, outros tratam das causas não contenciosas de seus clientes. Grande parte de suas tarefas estão voltadas para área não contenciosas: tratam-se de transferências de propriedades e da redação de documentos societários ou de testamentos.

A grande maioria presta adesão a uma associação, a Law Society, encarregada de organizar os exames que permite adquirir a qualidade de solicitor, cuja formação é de orientação prática. Muitos solicitors, depois de obterem seu diploma, entram nos ramos dos negócios ou da administração, onde seus conhecimentos são apreciados.

Convém notar a ausência na Inglaterra de uma instituição comparável ao nosso Ministério Público, que no entendimento dos ingleses é uma instituição que compromete o bom funcionamento da Justiça. Entendem que, se elevarmos o procurador ao nível de juiz, destrói-se a igualdade que deve ser respeitada entre acusação e defesa para assegurar uma justiça verdadeiramente imparcial.

$\mathrm{Na}$ Inglaterra há um número limitadíssimo de juízes que foram escolhidos entre os advogados de renome e a nomeação a uma função judiciária na Corte Superior sempre foi considerada como um sinal de fulgurante êxito, uma coroação numa carreira bem sucedida na advocacia. Estas circunstâncias fazem com que os juízes sejam personalidades carismáticas, o que possivelmente contribuiu para consolidação na Inglaterra do conceito de Poder Judiciário nesses moldes. Pouquíssimos juízes são membros permanentes das Cortes Superiores. Todos os juízes são vitalícios e, desde 1959, existe uma idade compulsória para aposentadoria, 75 anos. 


\subsection{AS PROFISSÕES JURÍDICAS NOS E.U.A.}

Historicamente, coube aos Estados da Federação a regulamentação da profissão jurídica, variando seus requisitos de um para o outro. Alguns exigiam dois anos colegiais e diploma de bacharel, outros, alternativamente, a prática em escritório de advocacia (raramente) ao invés do curso de Faculdade de Direito, e ainda, existiam os que, além do diploma de bacharel, exigem a prática de meio ano em escritório jurídico. Todos aplicam uma séria de exames escritos durante dois ou três dias, aperfeiçoados no tempo pelos esforços da Conferência Nacional dos Examinadores de Profissionais do Direito, e aprovando anualmente perto de dez mil pessoas. Não perdia a condição de advogado o fato de se tornar funcionário público, empregado de firma particular, ou professor de Direito, podendo regressar à sua banca. ${ }^{11}$

Durante o século XIX, a prática do Direito era mais geral que especializada, tendo como principal componente a representação em juízo. Mais do que a orientação jurídica, a especialização começou no final do século $\mathrm{XX}$, nas grandes cidades próximas aos centros financeiros, com o desenvolvimento de grandes negócios. Foi criada a Associação de Advogados, objetivando unir, coordenar e correlacionar as atividades de todos os membros, selecionando-os com o escopo de melhorar e fiscalizar a qualidade da atividade.

O trabalho do advogado começou a ser mais de orientação técnica e de preparação dos instrumentos jurídicos necessitando de conhecimento especializado. A média de consultores jurídicos é de dois em cada vinte advogados, empregados mediante salário fixo em empresas de negócios, geralmente firmas industriais, companhias de seguro e bancos, estando intimamente familiarizados com os problemas e condições peculiares da empresa e podendo atuar como membro de comissões ou mesmo da diretoria. Sua principal utilidade é como orientador, mais do que defensor. ${ }^{12}$

Segundo Griwold ${ }^{13}$, há alguns elementos de separação na carreira de advogado nos Estados Unidos. Aqueles que tinham sido chamados para o Fôro (Bar) na Inglaterra, eram

\footnotetext{
${ }^{11}$ FARNSWORTH, E. Allan. Introdução ao sistema jurídico dos Estados Unidos, Rio de Janeiro: Forense, 1963 , p. 29.

12 BARRETO FILHO, Oscar. Novos métodos de ensino do Direito: a experiência norte-americana. Revista Forense, Rio de Janeiro: Forense, 1970, p. 382-389.

${ }^{13}$ GRISWOLD, E. N. O direito e os advogados nos Estados Unidos. Rio de Janeiro: Forense, 1967. p. 16.
} 
considerados barristers. Aqueles que eram treinados por outros advogados eram admitidos como attorneys.

Em 1970, a Suprema Corte dos Estados Unidos estabeleceu que counsellors não poderiam praticar como attorneys e que estes não poderiam praticar como counsellors. Em 1801 tal restrição foi eliminada.

A designação solicitor nunca entrou em uso nos Estados Unidos e o barrister foi caindo em desuso quando não iam mais para Inglaterra estudar. Mais usual foi a utilização dos termos attorneys e consellors at law.

Os termos attorney, attorney-at-law, counsellor e counselor-at-law para denominar o advogado no direito americano não tem diferença de significado e, segundo Farnsworth ${ }^{14}$, "são empregados por motivos de elegância semântica".

Os advogados no serviço público, funcionários federais, estaduais e municipais (excluindo o Judiciário) geralmente são jovens bacharéis que consideram os salários atraentes para esse estágio de suas carreiras, além de lhes conferir uma boa prática profissional. As limitações salariais, no entanto, desencorajam alguns a continuar.

Os promotores federais, os procuradores da República, e seus assistentes são nomeados pelo Presidente e subordinados ao Procurador-Geral da República. Já os promotores estaduais são eleitos por distrito e os advogados ocupam-se diretamente dos assuntos jurídicos.

Nos Estados Unidos não existe um carreira judiciária, não havendo rumo prescrito para o bacharel que aspira ser juiz. Inicialmente devem trabalhar dois ou três anos como assessores dos principais juízes federais ou estaduais sem a promessa de uma carreira judicial como garantia.

O método de seleção de juízes adotado em mais de 2/3 dos Estados foi o voto popular, que tem sido muito reprovado. A Associação dos Advogados Norte-Americanos tem propugnado a análise das qualificações dos candidatos, escolhidos por uma comissão especial que prepara uma lista, e o Governador, dentre os nomes apresentados nesta lista, nomeia os juízes que escolher, candidato à reeleição por voto popular. Em poucos Estados a nomeação pelo Governador se sujeita à confirmação legislativa, método também utilizado para a classificação dos juízes federais, nomeados pelo Presidente e sujeitos à confirmação do Senado.

${ }^{14}$ FARNSWOTH, E. Allan. Introdução ao sistema jurídico dos Estados Unidos Rio de Janeiro: Forense, p. 32

Revista de Pesquisa e Educação Jurídica | e-ISSN: 2525-9636 | Curitiba | v. 2 | n. 2 | p. 85 - 104| Jul/Dez. 2016. 
A carreira judiciária tem como característica a exceção da vitaliciedade, e os juízes servem por um período determinado. Nos Tribunais de Jurisdição Geral a regra é servir quatro ou seis anos, e nas Cortes de Apelação, seis ou oito anos, cuja reeleição se dá por voto popular daqueles juízes que obtiveram um trabalho satisfatório.

Todas as Universidades mantém um programa de estudos avançados conducentes à obtenção de graus de pós-graduação, e que consiste, essencialmente, em cursos de especialização e em estudos e pesquisas independentes. Os graus conferidos pelos estudos graduados são os de Mestre (máster) em leis (L.L.M.), obtido após o mínimo de um ano de estudo graduado, e o de Doutor em Ciências Jurídicas (J.S.D.), obtido após três ou mais anos de estudo e de trabalho, sendo direcionados para a formação e preparo dos candidatos ao magistério do Direito.

Os advogados militantes geralmente partem para docência. Os títulos mais comuns são de professor assistente, professor associado e professor. As principais Escolas de Direito, com poucas exceções, exigem que seus professores dediquem tempo integral ao ensino e à pesquisa, abandonando a prática regular da advocacia.

Hodiernamente, as normas que regulamentam a profissão do advogado apresentam-se fragmentadas devido à multiplicidade de fontes competentes das quais emanam regras e estatutos. ${ }^{15}$ A advocacia é regulada por pelo menos cinco fontes, a saber: (1) Canons of Conduct e Model Codes/Rules, elaborados pela ABA; (2) juramento profissional perante à Corte; (3) regras específicas contidas em Leis Processuais Civis; (4) precedentes de conselhos disciplinares; (5) o poder das Cortes sobre a bar association de sua jurisdição. ${ }^{16}$

Superada a fase de explanação das profissões jurídicas, sem a pretensão de esgotar o tema, passa-se ao estudo específico da American Bar Association (EUA) e dos Inns Of Court (Inglaterra).

\subsection{INNS OF COURT}

15 FLETCHER, George P.; SHEPPARD, Steve. American Law in a Global Context. New York: Oxford University Press, 2005. Adobe digital edition. FREEMAN, Morton S. (Ed.). A New Dictionary of Eponyms. Oxford University Press, $1997 . \quad$ Disponível em: http://www.oxfordreference.com/view/10.1093/acref/9780195093544.001.0001/acref-9780195093544 . Acesso em: 20/03/2016.

${ }^{16}$ Idem p. 217 
O ensino inglês apresenta um caráter particular. Além das Universidades de Oxford, Cambridge e Manchester, existe a Universidade de Londres, mais moderna, mas todas conferindo diplomas correspondentes ao grau de bacharel e de doutor em Direito.

Os estudantes que se destinam às carreiras jurídicas passam pelo "Inns of Court", onde estudam, sobretudo, a common law e a prática do foro, para que possam tornar-se barristers.

A organização do Inns Of Court (albergues da Corte) eram assim chamados porque tratavam-se de seminários dos Tribunais ou Cortes de Justiça, encontrando-se descritas em Blackstone e em Franqueville - Sistema Judiciário da Grã-Bretanha, e compreendem:

a) Ao Inner Temple;

b) Ao Middle Temple;

c) Ao Lincoln's Inn;

d) Além de alguns Inns Of Chancer, onde os estudantes podem começar seus estudos para completar sua educação profissional nos Inns of Court.

Segundo os Regulamentos de 1875 e 1892, o plano de cursos compreende; $1^{\circ}$ ) Direito Romano e Direito Internacional Público e Privado; $2^{\circ}$ ) Direito Constitucional da Inglaterra e das Colônias; $3^{\circ}$ ) Direito Inglês, isto é, a common law e a statute law, compreendendo o direito das pessoas, o direito da propriedade móvel e imóvel, o direito das obrigações, o processo civil, o direito penal e o processo criminal.

Os advogados são necessariamente membros de um desses quatro clubes de advogados existentes em Londres, explica R. David ${ }^{17}$. O mesmo ocorre se residem e atuam em alguma cidade do interior. Essa circunstância merece ser observada. De fato, daí resulta que os advogados constituem um meio muito homogêneo, um círculo restrito em que todos se conhecem e onde uma infração disciplinar, ou mesmo ética, é severamente julgada.

Em seus Inns of Court os advogados se encontram e também conversam com os juízes, que permanecem em seu clube de origem quando deixam de ser advogados. O fato de pertencer ao mesmo clube gera certas atitudes e um sentimento de confiança que permite garantir um melhor funcionamento da Justiça na Inglaterra.

É um sistema objeto de críticas por Blackstone, que censurou o método empregado no Inns Of Court. Mais tarde, em 1948, Lord Brougham, em um Select Committee on Legal Educacion Report notava que o advogado e o juiz, formados sem base filosófica, resolvem as

${ }^{17}$ DAVID, Rene. O Direito Inglês. São Paulo: Martins Fontes, 1997. p. 33 
dificuldade por precedentes, sem revelar qualquer argumento fundado nos princípios das ciências e das leis.

Salienta ainda Blackstone, que um homem, educado para o foro, verá que, se a prática é tudo o que lhe fora ensinado, é também tudo que ele saberá: se não estiver instruído dos elementos e dos princípios sobre os quais são fundadas as regras da prática, a menor variante nas relações jurídicas o pertubará e o extraviará. Jamais se deve aspirar e formar novas teorias, bem como, compreender um argumento, sendo este deduzido do espírito das leis e dos fundamentos naturais da Justiça.

Denota-se uma gradativa mudança na aplicação do método indutivo, voltada em especial para o preparo filosófico do profissional, que deve abandonar o trabalho pautado apenas na memória de casos análogos.

\subsection{A AMERICAN BAR ASSOCIATION (EUA)}

$\mathrm{Na}$ busca por uma mudança na qualidade da educação dos advogados e na ética de suas condutas, foi fundada em 1878 a American Bar Association nos Estados Unidos da América, que estabeleceu requisitos de admissibilidade ${ }^{18}$ e desenvolveu uma política que gradativamente melhorou a qualidade da profissão jurídica. Destarte, o surgimento da entidade forneceu uma "identidade profissional" dando início ao profissionalismo na cultura jurídica norte-americana. ${ }^{19}$

No decorrer dos anos, as falhas de limitações nos requisitos de admissibilidade foram corrigidos, e eventuais falhas da entidade foram objeto de julgamento pela Suprema Corte. ${ }^{20}$

Consoante extraiu-se do estudo da organização judiciária dos EUA, existe a autonomia legislativa em cada Estado, e via de consequência, as regras de admissão à Bar Association são promulgadas pelas Cortes Especiais Estaduais. ${ }^{21}$ Em que pese a American

\footnotetext{
${ }^{18}$ Os requisitos de admissibilidade promoveram a limitação do acesso principalmente dos estrangeiros, das minorias raciais e das mulheres à carreira jurídica.

${ }^{19}$ MENKEL-MEADOW, Carrie. Lawyers. In: HALL, Kermit L. (Org.). The Oxford Companion to American Law. Oxford University Press, 2002. Disponível em: http://www.oxfordreference.com/view/10.1093/acref/9780195088786.001.0001/acref-9780195088786. Acesso em: 21/03/2016.

${ }^{20}$ Em 1977 a Supreme Court considerou inconstitucional regra da bar associations proibindo anúncios de advogados na televisão, rádio ou jornais (Bates v. State Bar of Arizona)

${ }^{21}$ DAVID, Rene. Grandes sistemas do direito contemporâneo. 4. ed. São Paulo: Martins Fontes, 2002. p. 485.
} 
Bar Association ser uma entidade privada e portanto, sem poder para imposição de suas regras, a maioria das Supreme Courts estaduais segue as disposições por ela estabelecidas.

A regulamentação da profissão jurídica pode ocorrer por outros meios ${ }^{22}$. Mas via de regra, o exercício da prática do Direito depende da submissão ao bar exam, uma prova de admissão perante a Bar Association ${ }^{23}$ (Ordem dos Advogados) do Estado no qual pretende atuar.

No caso das Cortes Federais, inexiste um exame próprio ${ }^{24}$. O mesmo ocorre com a Supreme Court de cada Estado. Nesses casos, é satisfatório que o candidato tenha atuado em período superior a três anos na mais Alta Corte de um estado, território ou no Distrito de Columbia; além de atestar que não sofreu sanção disciplinar e provar conduta de bom caráter moral e profissional. Obtendo êxito, finaliza-se o processo do oath of admission (juramento/compromisso de admissão). ${ }^{25}$

É importante destacar que somente com graduação em uma Law School aprovada pela American Bar Association é possível prestar o bar exam, sendo este um pré-requisito. Além do exame escrito, o candidato submeter-se-á a um exame de Moral Character and Fitness (Saúde e Caráter Moral). Tal processo investigativo desenrola-se consoante ao princípio do due process of law (devido processo legal) e da confidencialidade de fontes e dados. O ônus probatório (burden of proof) é de responsabilidade do candidato, que deverá fornecer os documentos exigidos.

\section{AS PRINCIPAIS ESCOLAS DE DIREITO}

Como visto nos tópicos anteriores, o sistema de ensino e a metodologia adotada pelas escolas de Direito influenciam diretamente na carreira jurídica do indivíduo, pelo que, oportuno é verificar os aspectos relevantes das principais faculdades nos EUA e na Inglaterra.

\footnotetext{
${ }^{22}$ Como é o caso dos Restatements of the Law, que se trata de uma compilação sistematizada das case-law.

${ }^{23}$ A American Bar Association é considerada atualmente a maior associação profissional voluntária no mundo, com aproximadamente 400.000 membros.

${ }^{24}$ GILLERS, Stephen. The Legal Profession. In: Morrison, Allan (Org.). Fundamentals of American Law. New York: Oxford University Press, 1998. p. 153.

${ }_{25}$ Augustyn, Noel J. Admission To Practice Before the Bar of the Court. In: HALL, Kermit L. (Org.). The Oxford Companion to the Supreme Court of the United States. Oxford University Press, 2005. Disponível em: http://www.oxfordreference.com/view/10.1093/acref/9780195176612.001.0001/acref9780195176612 . Acesso em: 16/03/2016.
} 


\subsection{NOS E.U.A.}

Em meados do século XIX, a educação jurídica nos E.U.A. estava confiada aos práticos, como era na Inglaterra. O método adotado, geralmente, era o da leitura do direito, principalmente dos comentários de Blackstone e de Kent.

O Ministro Joseph Story reorganizou a escola de Direito de Harvard, em 1829, 12 anos após a sua fundação. A atual organização das Faculdades de Direito dos EUA baseiamse nessas reformulações.

Story separou a formação jurídica da cultura geral e o Direito passou a ser ensinado supondo-se que o estudante já possuía conhecimentos gerais suficientes. Esses cursos tinham duração de um ou dois anos, não exigiam requisitos acadêmicos de admissão e não havia verificação do grau de conhecimento geral do estudante. Na primeira metade do século, considerava-se que todos os homens tinham o direito natural de praticar o Direito. ${ }^{26}$

Com a fundação da Associação dos Advogados Norte-Americanos, em 1878, o cenário mudou e os requisitos de admissão sofreram substanciais mudanças no decorrer do tempo, aperfeiçoando a educação jurídica no país.

Conforme explanam Farnsworth ${ }^{27}$ e Soares ${ }^{28}$, o estudante norte americano geralmente termina o curso escolar, secundário (High School), que é o último nível da escolaridade obrigatória, com idade entre 17 e 18 anos. Busca então, admissão em uma universidade estadual ou particular, na qual recebe educação colegial (college, estabelecimento isolado de nível universitário) ou universitária (university, estabelecimento que congrega a universidade de conhecimentos), até o grau de bacharel.

Explicam ainda, que a admissão no curso universitário, denominado nos EUA de undergraduate (no Brasil, curso de graduação) e ocorre através de exame de seleção, nos quais o mais importante é o exame das notas obtidas na High School. Dependendo do curso universitário pode-se levar de quatro ou mais anos para a sua conclusão, em geral, com a idade de 21 ou 22 anos, para obter o grau de bacharel. O sistema é de créditos, que podem ser integralizados com cursos de férias (summer course). O curriculum é elaborado de forma que

\footnotetext{
${ }^{26}$ A Constituição de Indiana(1851 a 1933) dispôs: “Toda pessoa de bom caráter moral, sendo eleitor, estará autorizada à prática do Direito em todos os tribunais de justiça”.

${ }^{27}$ FARNSWORTH, E. Allan. Introdução ao sistema jurídico dos Estados Unidos, Rio de Janeiro: Forense, 1963, p.23.

${ }^{28}$ SOARES, Guido F. S. Common law - introdução ao Direito dos Estados Unidos. São Paulo: Revista dos Tribunais, 1999, p. 65.
} 
o estudante obtenha conhecimento geral de algumas matérias e conhecimento especializado em outras.

O próximo passo é, então, a admissão em uma Law School (Faculdade de Direito no nosso sistema romano-germânico) através da aprovação em um exame de seleção nacional organizado e aplicado pelas Faculdades de Direito norte-americanas, que, juntamente com a American Bar Association, exercem um rigoroso controle de nível e condições de ensino. São critérios de seleção: a) histórico escolar (college record); b) um exame racional, hoje adotado pelas maiorias das escolas, destinado a verificar a aptidão para o estudo jurídico, capacidade de redação e conhecimentos gerais; c) outros critérios, como testes psicológicos e entrevistas pessoais.

Apesar de sua diversidade, as Faculdades de Direito norte-americanas têm duas características comuns: o nível universitário e o objetivo profissional. A Associação dos Advogados norte-americanos aprovou a maioria das Faculdades de Direito.

A Universidade pode ser particular (Harvard, Pennsylvania, Yale, Princeton e Columbia) ou controlada pelo Estado (Universidades de Virgínia, Michigan, Estado de Nova York, Califórnia, Texas e Washington).

A Faculdade pode ser uma escola de Direito local, na qual seus estudantes são originários da região onde ela está situada e, portanto, ali pretendem exercer a profissão. Por essa razão, há a tendência de direcionar o estudo das leis locais e dos problemas regionais. Ela pode também, ser nacional, preparando seus estudantes para a prática geral em todos os Estados. As escolas de Harvard, Yale, Columbia e algumas outras têm a finalidade de preparar os estudantes para a prática da advocacia em todos os Estados, em âmbito nacional e internacional.

\subsection{NA INGLATERRA}

Analisando o ensino nas Universidades, observa-se que a Inglaterra não adota o "case method" em sua pureza, como ocorre com os americanos, embora os ingleses também atribuam muita importância ao estudo do Direito pela indução de casos, como bem assevera Harriet C. Zitscher ${ }^{29}$ :

${ }^{29}$ ZITSCHER, Harriet C. Metodologia do Ensino Jurídico com casos - teoria e prática. Belo Horizonte: Editora Del Rey, 1999. 
(...) com esses métodos de aplicação do direito é fácil entender que o ensino também é dedicado ao caso concreto. Tal tendência é reforçada pela forte influência das profissões no ensino universitário (...) uma grande parte do ensino concentra-se em analisar, entender e saber de cor os casos mais importantes de cada matéria. As provas universitárias contêm uma quota considerável de casos práticos que devem ser solucionados pelos candidatos Acrescenta R. David ${ }^{30}$, quando trata das universidades inglesas, que:

(...) enquanto os juristas do continente europeu recebiam a sua formação nas universidades, na Inglaterra acontecia de forma diferente. O processo inglês não se opunha somente à influência do direito romano: a sua complexidade desencorajava os juristas a irem receber nas universidades uma aprendizagem de princípios, que não lhes serviria para nada na prática, na qual não se ouviam falar em direito romano, mas onde a sua atenção era constantemente chamada para as questões de processo e de prova, das quais dependiam o sucesso e a própria admissibilidade de uma nação.

Destarte, pode-se afirmar que o Direito na Inglaterra não é um Direito de universidades nem um Direito de princípios, e sim, um Direito de processualistas e de práticos. A preocupação com o processo coloca-se no primeiro plano das preocupações dos juristas da Inglaterra.

Entretanto, parece-nos que o caminho na Inglaterra comporta uma mudança de cenário, pois os processos tornaram-se mais simples, e conforme explica R. David ${ }^{31}$ :

(...) o direito inglês enriqueceu-se consideravelmente quanto à sua essência e adquiriu um rigor comparável ao dos direitos do continente europeu. Os juristas ingleses frequentam cada vez mais os cursos de Direito nas universidades, para aprender os princípios que foram sistematizados nos nossos dias, de maneira totalmente semelhante aos princípios dos diferentes direitos românicos.

Entre as faculdades mais tradicionais da Inglaterra encontram-se: Manchester Law Facult (fundada em 1851, localizada fora de Londres); Westminster Law (localizada no coração de Londres); The Facult of Law na University of Oxford (faculdade de elite inglesa, sendo que o common law começou a ser estudada em 1758); School of Law na Boston University (fundada em 1872).

É oportuno destacar que o método, até mesmo os EUA, está sendo revisto nas universidades de Direito, onde o pensamento volta-se pela adoção, total ou parcial, de um método a partir dos problemas.

${ }^{30}$ DAVID, Rene. O Direito Inglês. São Paulo: Editora Martins Fontes, 1997, p. 307

${ }^{31}$ DAVID, Rene. Os grandes sistemas do direito contemporâneo, p. 321 


\section{CONSIDERAÇÕES FINAIS}

Em linhas gerais, verificamos que a advocacia norte-americana e inglesa possuem suas características perfeitamente adaptadas ao seu sistema de governo, à divisão territorial e à espécie de Estado vigente.

Portanto, nesse aspecto, o ensino nacionalizado, como é o inglês, assemelha-se ao brasileiro uma vez que, ressalvados alguns casos, como os de natureza tributária por exemplo, o direito local não se sobrepõe à imensa aplicação do direito vigente em todo território.

Em outro aspecto, apesar de existir em todos os países uma entidade superior que regule as atividades da advocacia, no Brasil ele não sofre ingerência do Poder Judiciário na aprovação de suas normas.

Em relação ao acesso às faculdades de Direito, nas brasileiras, a entidade superior que disciplina e físcaliza o exercício da advocacia (Ordem dos Advogados do Brasil) não exerce influência sobre a admissão e nem controla a qualidade do ensino.

Também o ensino de Direito no Brasil não diferencia o ensino para a prática da advocacia e da docência, não se preocupando com a formação de docentes, como ocorre na Inglaterra, pelo que o concluinte recebe o título de bacharel e o inglês pode ainda conferir o de doutor.

$\mathrm{Na}$ carreira judicial a forma de ingresso no Brasil no Poder Judiciário é muito diferente da americana, não havendo aqui o acesso por meio de eleição.

Por fim, uma característica que diferencia o ensino do Direito no Brasil, de tradição romano-germânica, e dos E.U.A. e da Inglaterra, que adotam o sistema jurisprudencial, é método utilizado para interpretação do Direito. Enquanto na common law o precedente judicial tem suma importância para as decisões do Judiciário, no Brasil, embora a jurisprudência exerça uma grande influência na forma de interpretação, o ensino encontra base precípua na legislação.

Pelas diferenças que cada sistema jurídico apresenta, é preciso muito cuidado nas comparações entre os dois sistemas, não sendo possível a transposição ou utilização simples de regras umas das outras para modificação e aperfeiçoamento do ensino jurídico e, via de consequência, das profissões dela decorrentes. 


\section{REFÊRENCIAS BIBLIOGRÁFICAS}

AUgustyn, Noel J. Admission To Practice Before the Bar of the Court. In: HALL, Kermit L. (Org.). The Oxford Companion to the Supreme Court of the United States. Oxford University Press, 2005.2 Disponível em: http://www.oxfordreference.com/view/10.1093/acref/9780195176612.001.0001/acref9780195176612 . Acesso em: 16/03/2016.

BARRETO FILHO, Oscar. Novos métodos de ensino do Direito: a experiência norteamericana. Revista Forens., Rio de Janeiro: Forense, 1970

DAVID, Rene. Grandes sistemas do direito contemporâneo. 4. ed. São Paulo: Martins Fontes, 2002.

DAVID, Rene. O Direito inglês. São Paulo: Martins Fontes, 1997.

FARNSWORTH, E. Allan. Introdução ao sistema jurídico dos Estados Unidos, Rio de Janeiro: Forense, 1963.

FEDERAL JUDICIAL CENTER. Sistema jurídico dos Estados Unidos: uma breve descrição. Disponível em: http://www.fjc.gov/public/pdf.nsf/lookup/Portuguese01.pdf/\$file/Portuguese01.pdf Acesso em $12 / 03 / 2016$.

FLETCHER, George P.; SHEPPARD, Steve. American Law in a Global Context. New York: Oxford University Press, 2005. Adobe digital edition. FREEMAN, Morton S. (Ed.). A New Dictionary of Eponyms. Oxford University Press, 1997. Disponível em: http://www.oxfordreference.com/view/10.1093/acref/9780195093544.001.0001/acref9780195093544 . Acesso em: 20/03/2016.

GILLERS, Stephen. The Legal Profession. In: Morrison, Allan (Org.). Fundamentals of American Law. New York: Oxford University Press, 1998

GRISWOLD, E. N. O direito e os advogados nos Estados Unidos. Rio de Janeiro: Forense, 1967.

MENKEL-MEADOW, Carrie. Lawyers. In: HALL, Kermit L. (Org.). The Oxford Companion to American Law. Oxford University Press, 2002. Disponível em: http://www.oxfordreference.com/view/10.1093/acref/9780195088786.001.0001/acref9780195088786. Acesso em: 21/03/2016.

SOARES, Guido F. S. Common law - introdução ao Direito dos Estados Unidos. São Paulo: Revista dos Tribunais, 1999. 
TUCCI, José Rogério Cruz e (coord.). Direito processual civil europeu contemporâneo. São Paulo: Lex, 2010.

ZITSCHER, Harriet C. Metodologia do Ensino Jurídico com casos - teoria e prática. Belo Horizonte: Editora Del Rey, 1999. 